\title{
A Recombinant of Bean common mosaic virus Induces Temperature- Insensitive Necrosis in an I Gene-Bearing Line of Common Bean
}

\author{
Xue Feng, Alan R. Poplawsky, and Alexander V. Karasev
}

First, second, and third authors: Department of PSES, and third author: Bioinformatics and Computational Biology Program, University of Idaho, Moscow, ID.

Accepted for publication 17 May 2014.

\begin{abstract}
Feng, X., Poplawsky, A. R., and Karasev, A. V. 2014. A recombinant of Bean common mosaic virus induces temperature-insensitive necrosis in an $I$ gene-bearing line of common bean. Phytopathology 104:1251-1257.

The $I$ gene is a single, dominant gene conferring temperature-sensitive resistance to all known strains of Bean common mosaic virus (BCMV) in common bean (Phaseolus vulgaris). However, the closely related Bean common mosaic necrosis virus (BCMNV) induces whole plant necrosis in $I$-bearing genotypes of common bean, and the presence of additional, recessive genes is required to prevent this severe whole plant necrotic reaction caused by BCMNV. Almost all known BCMNV isolates have so far been classified as having pathotype VI based on their interactions with the five BCMV resistance genes, and all have a distinct serotype A. Here, we describe a new isolate of BCMV, RU1M, capable of inducing whole plant necrosis in the presence of the $I$ gene, that appears to belong to pathotype VII and exhibits B-serotype. Unlike other isolates of BCMV,

RU1M was able to induce severe whole plant necrosis below $30^{\circ} \mathrm{C}$ in bean cultivar Jubila that carries the $I$ gene and a protective recessive gene $b c-1$. The whole genome of RU1M was cloned and sequenced and determined to be 9,953 nucleotides long excluding poly(A), coding for a single polyprotein of 3,186 amino acids. Most of the genome was found almost identical (>98\%) to the BCMV isolate RU1-OR (also pathotype VII) that did not induce necrotic symptoms in 'Jubila'. Inspection of the nucleotide sequences for BCMV isolates RU1-OR, RU1M, and US10 (all pathotype VII) and three closely related sequences of BCMV isolates RU1P, RU1D, and RU1W (all pathotype VI) revealed that RU1M is a product of recombination between RU1-OR and a yet unknown potyvirus. A $0.8-\mathrm{kb}$ fragment of an unknown origin in the RU1M genome may have led to its ability to induce necrosis regardless of temperature in beans carrying the $I$ gene. This is the first report of a BCMV isolate inducing temperature-insensitive necrosis in an $I$ gene containing bean genotype.
\end{abstract}

Bean common mosaic virus (BCMV) and Bean common mosaic necrosis virus (BCMNV) are closely related members of the genus Potyvirus in the family Potyviridae (1). Both BCMV and BCMNV are important pathogens in common beans (Phaseolus vulgaris L.), both are transmitted by several aphid species in a nonpersistent manner, and also can be transmitted through seed with variable efficiencies depending on bean genotypes $(14,26,31)$. Interactions of BCMV and BCMNV isolates with common bean are governed by five resistance genes, one dominant $I$ gene, and four recessive genes, $b c-u, b c-1, b c-2$, and $b c-3$ (8). Genes $b c-1$ and $b c-2$ have two alleles each $\left(b c-1 / b c-1^{2}\right.$ and $\left.b c-2 / b c-2^{2}\right)$ for a total of seven alleles that interact with the different strains of BCMV/BCMNV.

Resistance to BCMV was first described in $P$. vulgaris 'Corbett Refugee' (29); it was later linked to a dominant I gene by Ali (2). Upon infection, cultivars of beans ( $P$. vulgaris) bearing the $I$ gene display either no symptoms or various types of necrosis. These necrotic reactions range from local necrotic lesions on inoculated leaves to systemic vein necrosis and sometimes plant death following the challenge with BCMV or closely related BCMNV. Two types of necrotic responses could be induced: (i) temperature-insensitive necrosis (TIN) refers to systemic vein necrosis or whole plant necrosis (also called black root reaction or "black root syndrome" [BRS]) induced by all BCMNV isolates at

Corresponding author: A. V. Karasev; E-mail address: akarasev@uidaho.edu

*The $e$-Xtra logo stands for "electronic extra" and indicates that Figures 3 and 4 appear in color online.

http://dx.doi.org/10.1094/PHYTO-02-14-0048-R

(c) 2014 The American Phytopathological Society all temperatures; and (ii) temperature sensitive necrosis (TSN) refers to a similar necrotic reaction induced by some BCMV isolates only at temperatures above $30^{\circ} \mathrm{C}(2,5,12,15,17,18,29,30)$. Bean genotypes that combine the dominant $I$ allele with recessive resistance alleles can confer effective strain-specific resistance to BCMV and BCMNV without inducing severe necrosis and plant death, resulting in the so-called "protected" I gene $(9,19)$.

BCMNV isolates can be easily distinguished from BCMV isolates biologically, due to necrotic reaction in $I$ gene-bearing bean lines $(8,32)$, and also serologically, having a distinct Aserotype, while BCMV isolates all exhibit B-serotype $(24,25,33)$. Sequence diversity among BCMNV strains was found to be limited, with strains NL-3, NL-5, NL-8, and TN-1 exhibiting 97 to $99 \%$ genomic sequence identity $(10,21)$. A single natural recombinant NL-3K was reported having a typical BCMNV genome with an approximate $0.34-\mathrm{kb}$ insert near the $5^{\prime}$-terminus coming from strain RU1 of BCMV $(22,32)$. This natural recombinant NL-3K displayed more severe symptoms on some bean host differential genotypes, but had the same pathotype VI as the parental isolate NL-3, and induced the necrotic reaction in the presence of the $I$ gene like NL-3 $(22,32)$. The viral genetic determinant(s) responsible for the $I$ gene mediated necrosis, or for exhibiting pathotype VI in beans have not been identified yet.

BCMV strains have been found to be much more diverse than BCMNV isolates, displaying not only biological diversity with seven pathotypes $(8,9)$ but whole genome sequence diversity as well $(11,13,22,28)$. Recent sequence analysis of a series of whole genome sequences of BCMV isolates related to strain RU1, which we referred to as the RU1 strain group, revealed that they often have recombinant genomes, and that recombinant events may result in biological changes shifting their pathotype specificity 
(11). The genome region spanning the P1 and HC-Pro cistrons was hypothesized to be involved in interactions with the $b c-2^{2}$ gene in common bean, thus defining the pathotype VII of BCMV (11). Genetic determinants of BCMV responsible for interactions with other resistance genes and specific mechanisms facilitating these interactions have yet to be elucidated.

In this study, an unusual isolate of BCMV from the RU1 strain group, which we named RU1M, was characterized and found to induce severe whole plant necrosis regardless of temperature in bean cultivar Jubila that carries the $I$ gene. Here, we describe a biological, serological, and molecular characterization of this novel RU1M strain. Comparison of the biological and molecular properties of RU1M with other isolates having the same or differing pathogenicity on bean differentials allowed us to localize a putative genomic region that may condition interactions with the $I$ gene. Data presented here, together with previous studies, also allowed us to narrow down the putative genome region interacting with the recessive resistance gene $b c-2^{2}(11)$.

\section{MATERIALS AND METHODS}

Virus sources, propagation, and purification. All reference BCMV and BCMNV isolates used in this work originated from the USDA-ARS Prosser, WA, collection. Control BCMV strain
US10 (pathotype VII) and BCMNV strain TN1 (pathotype VI) were provided by P. Berger and P. Shiel (University of Idaho). The BCMV isolate designated by us as RU1M was originally obtained from P. Berger and P. Shiel and was described and partially characterized previously (4). Isolate RU1-OR (pathotype VII) was originally collected by J. Myers in Oregon and was described in detail previously (11). All BCMV and BCMNV isolates were propagated on bean cultivar Dubbele Witte and viruses were purified as described previously (11).

Biological and serological characterization. The biological characterization of RU1M on a set of bean differentials (8) was performed as described previously (11). Two reference strains, TN1 (pathotype VI) and US10 (pathotype VII), were included in this analysis as controls. Eleven bean differential lines carrying different resistance gene combinations (Table 1) were inoculated with each isolate (three replicates), and plants were placed in the greenhouse with standard summer-time growth conditions (16-h day photoperiod and daytime/nighttime temperatures of $25 / 20^{\circ} \mathrm{C}$ ). Uninoculated plants of each virus strain-host combination were used as controls. Symptoms were recorded at 4 weeks postinoculation (pi). In addition, at 4 weeks pi samples were collected for enzyme-linked immunosorbent assay (ELISA) testing.

RU1M virus preparations were purified from RU1M-infected bean cultivar Dubbele Witte according to the protocol described
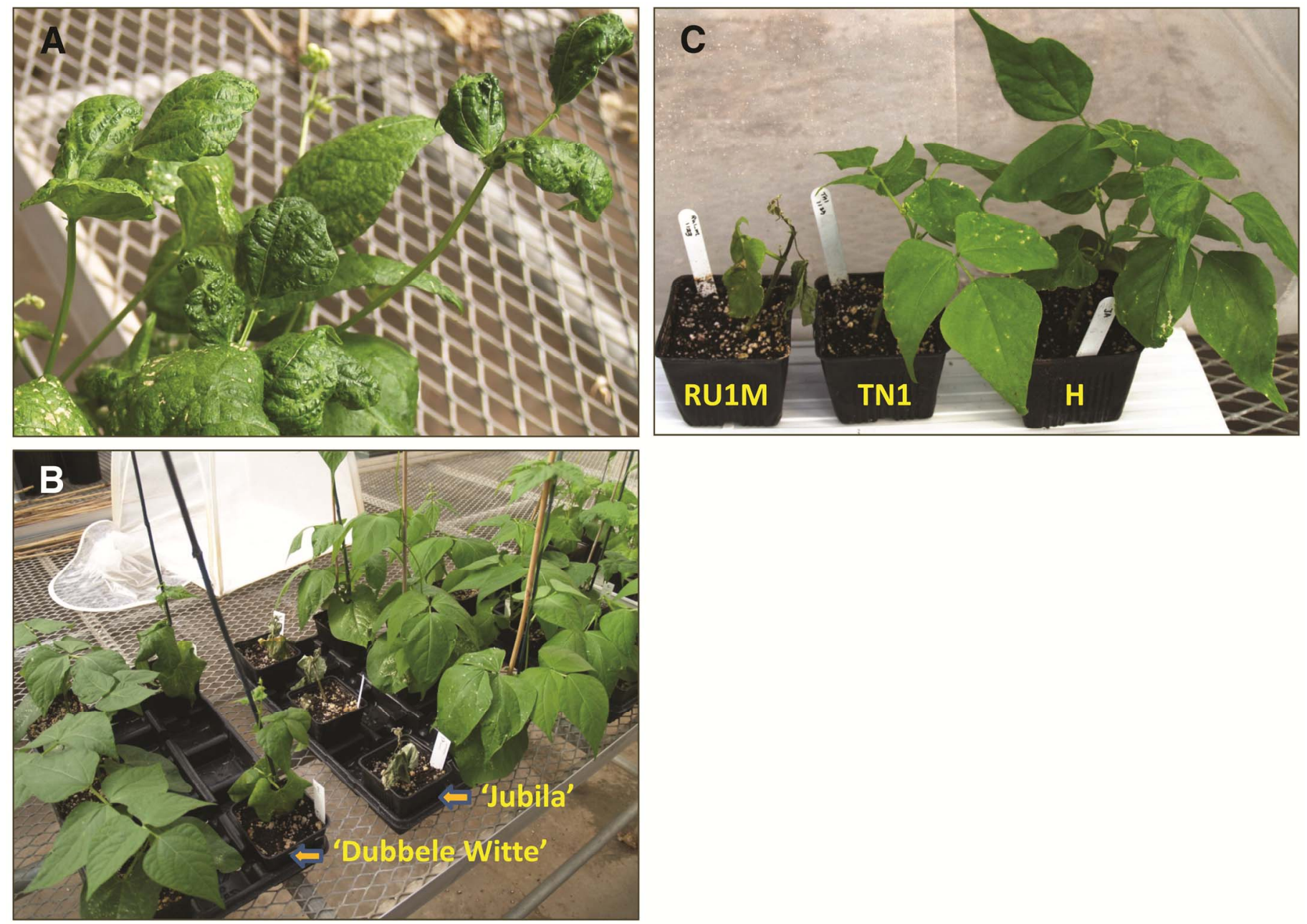

Fig. 1. Foliar symptoms induced in common bean (Phaseolus vulgaris L.). A, Bean plant infected with Bean common mosaic virus (BCMV) isolate RU1M, cultivar Dubbele Witte, displaying severe mosaic, blistering, and leaf deformations 6 weeks postinoculation. B, Whole plant necrosis and plant death induced by RU1M (indicated by an arrow) in three plants of cultivar Jubila (I,bc-1) 10 days postinoculation; two control plants of cultivar Dubbele Witte inoculated with RU1M at the same time are also indicated by an arrow. C, Side-by-side comparison of 'Jubila' (I,bc-1) plants inoculated with BCMV isolate RU1M and Bean common mosaic necrosis virus isolate TN1 at 2.5 weeks postinoculation; note the clear black root syndrome (BRS) or whole plant necrosis induced by RU1M and the absence of the BRS or any systemic necrotic reaction induced by TN1 by this time point; respective inoculum, RU1M or TN1, is labeled on each plant, $\mathrm{H}$ indicates healthy control. 
elsewhere (11); control virus preparations for isolates RU1-OR, RU1-P, and US10 were from the laboratory collection and were described previously (11). Triple-antibody sandwich (TAS)ELISA tests using BCMV and BCMNV strain-specific, polyclonal antibodies from the laboratory collection were performed as described (11).

Cloning strategy, sequencing, and sequence analysis. The cloning strategy, sequencing, and sequence analysis of BCMV isolates were all described previously (11). All primers used in this study for reverse transcription-polymerase chain reaction (RT-PCR) amplifications and sequencing are listed in Table 2. The whole genome sequence for BCMV isolate RU1M has been deposited in the GenBank database and appears under accession number KJ645793. The sequence was initially analyzed using the BLASTn 2.2.17 (3) tool available at the National Center for Biotechnology Information (NCBI). The complete viral genome was assembled using SeqMan (DNASTAR, Madison, WI). Open reading frames (ORFs) were identified using the ORF Finder program available at the NCBI website (http://www.ncbi.nlm. nih.gov/gorf/gorf.html). Complete sequences of BCMV isolates were aligned using ClustalX Version 2.0 (Conway Institute, UCD, Dublin). Further analysis was conducted with the Recombination Detection Program v.4.16 (RDP4) (23).

\section{RESULTS}

Biological characterization. When tested on the 11 bean differential lines, RU1M induced typical mosaic, raised dark green blistering, leaf deformation, and growth retardation in susceptible bean varieties (Fig. 1A and B; Table 1). Based on the pathogenicity profile exhibited by the RU1M isolate on bean differential lines, it appeared to exhibit pathotype VII (Table 1). Pathotype VII was previously found in one of the field isolates from the RU1 complex (11). Unexpectedly, systemic necrotic reactions were recorded upon inoculation of RU1M on bean cultivar Jubila $(I, b c-1)$ visible as BRS or whole plant necrosis and plant death which started at 7 to 10 days pi (Fig. 1B and C). No necrotic reactions were observed in Amanda, US 1006, or IVT 7233, even at 6 weeks after inoculation with RU1M (Table 1). Upon inoculation with the TN1 isolate of BCMNV, systemic necrotic reactions were recorded in bean cultivar Jubila; however, in this case systemic vein necrosis was visible only on some upper, uninoculated leaves, late in infection, and plants were alive and well even 6 weeks pi (Fig. 2). By the time 'Jubila' exhibited pronounced BRS induced by the RU1M infection, 2.5 weeks pi, systemic necrosis symptoms were not yet visible in 'Jubila' plants inoculated with the BCMNV isolate TN1 (Fig. 1C). These

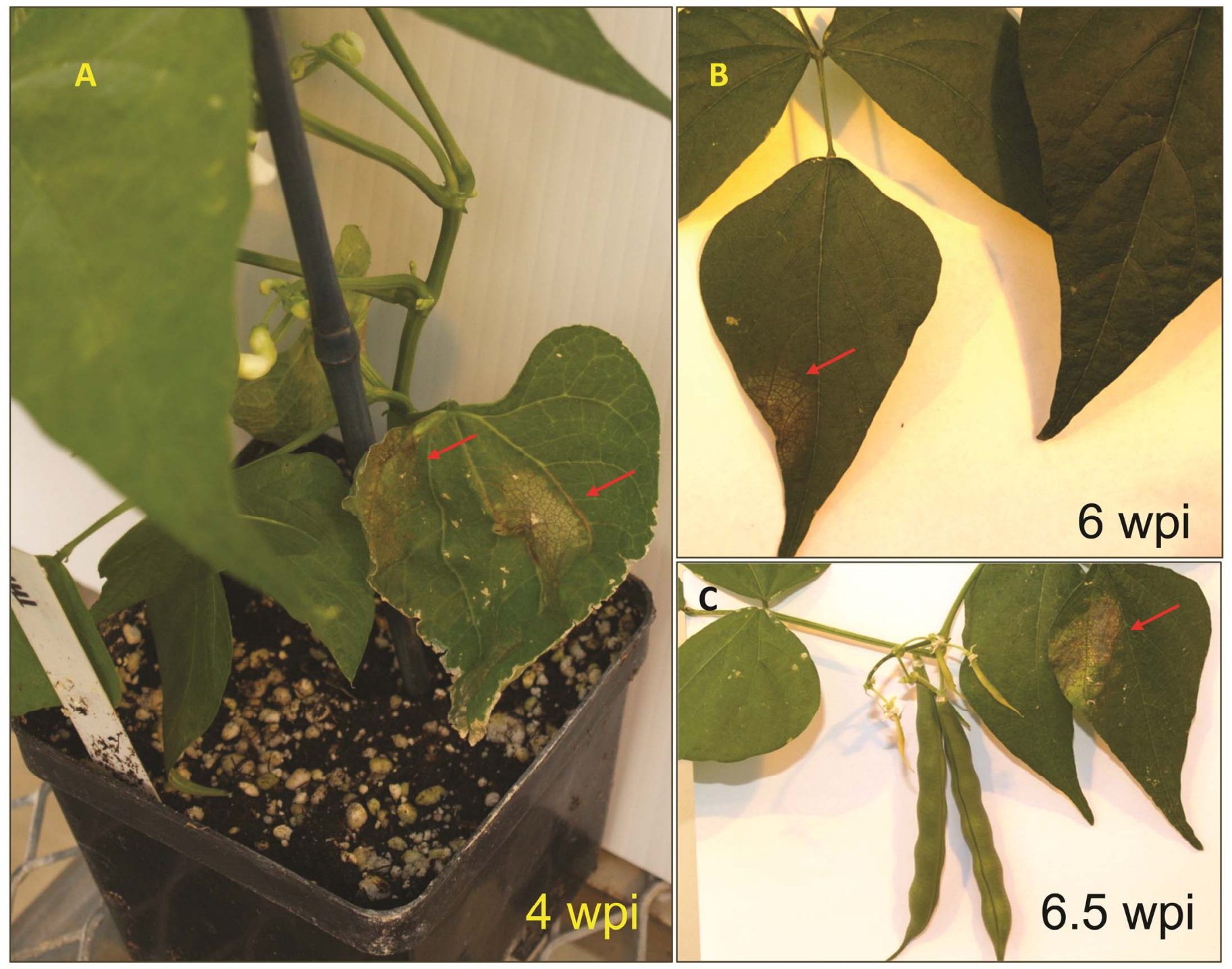

Fig. 2. Systemic necrotic reaction induced by the control Bean common mosaic necrosis virus (BCMNV) isolate TN1 in cultivar Jubila (I,bc-1) in upper, uninoculated leaves at various time points after inoculation: A, 4 weeks postinoculation (wpi); $\mathbf{B}, 6$ wpi; and $\mathbf{C}, 6.5$ wpi. Note the absence of the whole plant necrosis or black root syndrome at any time point postinoculation. 
systemic necrotic symptoms became visible only later at around 4 weeks pi, and were displayed as modest vein necrotic spots on some upper noninoculated leaves, which kept appearing through the entire experiment which was terminated at about 7 weeks pi (Fig. 2); by this time 'Jubila' plants inoculated with RU1M were long dead. No systemic symptoms were observed in Amanda, US 1006, and IVT 7233 harboring the $I$ gene upon inoculation with TN1. The presence of BCMV or BCMNV in inoculated plants was tested with TAS-ELISA (Table 1), and the results always agreed with the symptom expression. 'Jubila' plants infected with RU1M died at 10 to 14 days pi, providing no leaf tissue for ELISA tests; however, 'Jubila' plants inoculated with TN1 were virus-negative as determined by ELISA at 4 weeks pi (Table 1). Reference strains TN1 (pathotype VI) and US10 (pathotype VII) showed the expected virulence profiles with the differential lines based on their pathotypes. Isolate RU1M displayed a virulence profile identical to that of the pathotype VII reference strain US10, and distinct from the control isolate TN1 (pathotype VI, Table 1). In summary, isolate RU1M exhibited pathotype VII on the bean differentials; however, it also displayed an ability to

TABLE 1. Disease and enzyme-linked immunosorbent assay (ELISA) reactions of bean differentials inoculated with Bean common mosaic virus (BCMV) strains ${ }^{\mathrm{a}}$

\begin{tabular}{llccc}
\hline Bean cultivar & Resistance genes & TN1 (VI) & US10 (VII) & RU1M \\
\hline Dubble Witte & None & $+/+$ & $+/+$ & $+/+$ \\
SGR & $i, b c-u$ & $+/+$ & $+/+$ & $+/+$ \\
RGLC & $i, b c-u, b c-1$ & $+/+$ & $+/+$ & $+/+$ \\
RGLB & $i, b c-u, b c-1^{2}$ & $+/+$ & $+/+$ & $+/+$ \\
Sanilac & $i, b c-u, b c-2$ & $+/+$ & $-/-$ & $-/-$ \\
Othello & $i, b c-u, b c-1^{2}, b c-2^{2}$ & $-/-$ & $+/+$ & $+/+$ \\
IVT7214 & $i, b c-u, b c-2, b c-3$ & $-/+$ & $-/-$ & $-/-$ \\
Jubila & $I, b c-1$ & $n e c /-$ & $-/-$ & BRS/NA \\
Amanda & $I, b c-1^{2}$ & $-/-$ & $-/-$ & $-/-$ \\
US1006 & $I, b c-u, b c-2^{2}$ & $-/-$ & $-/-$ & $-/-$ \\
IVT7233 & $I, b c-u, b c-1^{2}, b c-2^{2}$ & $-/-$ & $-/-$ & $-/-$ \\
\hline
\end{tabular}

a Disease reaction is shown first as a numerator followed by ELISA reaction as a denominator. Two plants were inoculated for each BCMV strain; results shown are the same for both plants inoculated with each virus preparation. Numerator: $+=$ symptoms on inoculated beans; $-=$ no symptoms on inoculated beans; nec $=$ systemic necrotic reaction on some uninoculated leaves; and BRS = black root syndrome. Denominator: + indicates ELISA signal (absorbance at $405 \mathrm{~nm}\left[A_{405}\right]$ ) in an infected plant exceeding healthy control by 10 -fold or more; - indicates ELISA signal in an infected plant approximately equal to that of a healthy control; NA indicates not applicable, since the plant died before the test could be run. induce TIN in an $I$ gene-bearing cultivar Jubila $(I, b c-1)$. The intensity and time-course of this TIN was drastically different from that of the control isolate TN1 suggesting different types of interactions with the I gene between RU1M and TN1.

Serological characterization. Since BCMNV strains inducing necrosis in $I$ gene-bearing lines of beans all have a distinct Aserotype, the RU1M isolate was subjected to a serological characterization with TAS-ELISA side-by-side with reference strains US10 (BCMV, B-serotype) and TN1 (BCMNV, A-serotype) to determine if it belongs to BCMV or BCMNV. The serotyping data are summarized in Table 3. The anti-US10 antiserum reacted to all isolates tested, including RU1M, and also the BCMNV isolate TN1, when used as detecting antibody. The anti-TN1 antiserum reacted only with the homologous isolate TN1 when used as detecting antibody. The anti-NY15P and anti-RU1-OR antisera were capable of binding BCMV isolates RU1M and US10, but not BCMNV isolate TN1. The data presented in Table 3 were consistent with data from a previous study (11), and RU1M displayed the same serological properties as US10. The serological typing of RU1M as B-serotype was consistent with the preliminary characterization of this same isolate conducted previously by Berger et al. (4) who sequenced the 3 '-terminal $1.2 \mathrm{~kb}$ of the BCMV RU1 genome and showed the RU1 capsid protein (CP) to group with other B-serotype isolates of BCMV.

Whole genome cloning, sequencing, and sequence analysis. To determine the molecular basis of the unusual biological properties of the BCMV isolate RU1M, the whole genome of

TABLE 3. Serological characterization of Bean common mosaic virus (BCMV) isolates using strain-specific antibodies in triple-antibody sandwichenzyme-linked immunosorbent assay (ELISA) ${ }^{\mathrm{a}}$

\begin{tabular}{lccc}
\hline & \multicolumn{3}{c}{ BCMV strains } \\
\cline { 2 - 4 } Antibodies & TN1 & US10 & RU1M \\
\hline Pre-immune & - & - & - \\
Anti-NY15P & - & + & + \\
Anti-US10 & + & + & + \\
Anti-TN1 & + & - & - \\
Anti-RU1-OR & - & + & + \\
\hline
\end{tabular}

a RU1M and control isolates were captured on the ELISA plates using either anti-TN1, anti-US10, anti-RU1-OR, or anti-NY15p rabbit antiserum, and were subsequently probed with the different detecting antibodies generated in guinea pig. + indicates ELISA signal (absorbance at $405 \mathrm{~nm}\left[A_{405}\right]$ ) in an infected plant exceeding healthy control 10 -fold or more; - indicates ELISA signal in an infected plant approximately equal to that of a healthy control.

TABLE 2. Primers used for cloning the whole Bean common mosaic virus genome

\begin{tabular}{|c|c|c|}
\hline Primer & Sequence $\left(5^{\prime}-3^{\prime}\right)$ & Use \\
\hline \multicolumn{3}{|l|}{ Degenerate primers ${ }^{\mathrm{a}}$} \\
\hline HPFor & TGYGAYAAYCARYTIGAYIIIAAYG & Degenerate primer to amplify partial HC-Pro gene \\
\hline HPRev & GAICCRWAIGARTCIAIIACRTG & Degenerate primer to amplify partial HC-Pro gene \\
\hline CIFor & GGIVVIGTIGGIWSIGGIAARTCIAC & Degenerate primer to amplify partial CI gene \\
\hline CIRev & ACICCRTTYTCDATDATRTTIGTIGC & Degenerate primer to amplify partial CI gene \\
\hline NIbFor & GGICARCCITCIACIGTIGT & Degenerate primer to amplify partial nib gene \\
\hline \multicolumn{3}{|r|}{ 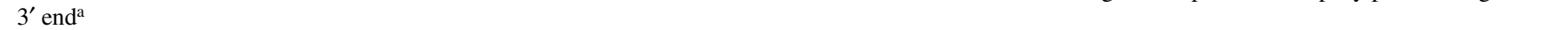 } \\
\hline $\mathrm{N} 1 \mathrm{~T}$ & GACCACGCGTATCGATGTCGAC $(\mathrm{T})_{17} \mathrm{~V}$ & Generic $3^{\prime}$ end first-strand primer \\
\hline N1 & GACCACGCGTATCGATGTCGAC & Generic $3^{\prime}$ end PCR primer \\
\hline \multicolumn{3}{|c|}{ (20) } \\
\hline Oligo $\mathrm{d}(\mathrm{T})$ anchor primer & GACCACGCGTATCGATGTCGAC $(\mathrm{T})_{16} \mathrm{~V}$ & \\
\hline \multicolumn{3}{|l|}{ RU1M specific primers } \\
\hline RU1M mg1 For & CAACAACTTCTCGCAACCAACCAC & Specific primer to amplify the major gap 1 \\
\hline RU1M mg1 Rev & CCCTTTGCCCATTAGGATTCCTCC & Specific primer to amplify the major gap 1 \\
\hline RU1M mg2 For & GAGTCCAACTAAGAGACACC & Specific primer to amplify the major gap 2 \\
\hline RU1M mg2 Rev & CACGTCCTGGTGGTGTTGCTGATAC & Specific primer to amplify the major gap 2 \\
\hline RU1M mg3 For & GTATCAGCAACACCACCAGGACGTG & Specific primer to amplify the major gap 3 \\
\hline RU1M mg3 Rev & TCCGGTGAAGTGCCATTGTCAATAC & Specific primer to amplify the major gap 3 \\
\hline RU1M 5RACE Rev1 & CCTGCGTCACTGATGAACCTTTC & First-strand primer for $5^{\prime} \mathrm{RACE}$ \\
\hline RU1M 5RACE Rev2 & CGTGCAGAAGTTGGTTTTGGATTCATGTAAATGCGCTCTTGTG & PCR primer for $5^{\prime} \mathrm{RACE}$ \\
\hline
\end{tabular}

\footnotetext{
a All degenerate primers and $3^{\prime}$ end primers are from Ha et al. (16).
}

b $5^{\prime}$ end anchor primer is from the $5^{\prime}$ RACE kit protocols. 
RU1M was cloned and sequenced, using the approach described previously (11). Upon sequence assembly, RU1M was found to be 9,953 nucleotides long, excluding the poly(A). Based on conceptual translation, the BCMV RU1M genome encoded a single polyprotein of 3,186 amino acids. Initially, the sequence of RU1M was compared with the known BCMV and BCMNV genomes using the BLAST 2.2.17 tool (3), and this revealed that the RU1M sequence shared the closest similarity to the isolate RU1-OR (accession numbers KF919297 or KF919298; 98\% nucleotide identity), except for a $0.8-\mathrm{kb}$ fragment near the $5^{\prime}$ terminus (described below).

The whole genomes for RU1M (accession number KJ645793), RU1-OR-b (KF919297), RU1-OR-c (KF919298), and US10 (KF919299) all having pathotype VII, together with RU1P (KF919300), RU1W (AY863025), and RU1D GQ219793) all having pathotype VI, were aligned using CLUSTALX and further analysis was conducted with the RDP4 program package. Figure 3 shows the comparison of all known RU1 whole genome sequences plus the sequence of US10 using the manual distance plot analysis, with the full-length BCMV RU1D sequence from GenBank as the reference (Fig. 3).

Based on the RDP4 analysis, the 5'-terminal sequences of isolates RU1M and RU1-OR, nucleotides 1 to 512 , were not very similar to each other ( $86 \%$ identity) or to all other isolates, RU1D, RU1W, RU1P, and US10 (84 to $85 \%$ identity, Fig. 3). On the other hand, the 5 '-terminal genome segments were very similar between the latter four isolates (96\% identity) (Fig. 3). Remarkably, RU1M was found to have an insert in its genome, between nucleotides 513 to 1287 , with no close relationships to BCMV or BCMNV nucleotide sequences available in the GenBank database (Fig. 3). When this segment of the RU1M genome, between positions 513 to 1287 , was conceptually translated and the resulting amino acid sequence compared with the protein sequences available in the GenBank database using the BLASTP program, the closest matches were the $\mathrm{P} 1$ regions of polyproteins coded by isolates of Cowpea aphid-borne mosaic virus (CABMV; 50 to $58 \%$ identity) and isolates of BCMNV (35 to $36 \%$ identity). Downstream of this insert in RU1M, between nucleotides 1348 to 2006 (position in alignment), sequences of all six isolates analyzed were found to show close similarities to each other (Fig. 3). Specifically, the three isolates belonging to pathotype VI, RU1W, RU1D, and RU1P exhibited $>99 \%$ identity to each other, and the three isolates belonging to pathotype VII, RU1M, RU1-OR, and
US10, exhibited more than $97 \%$ identity to each other, while pathotypes VI and VII in this same region were $96 \%$ identical. In the 3'-terminal region, downstream of nucleotide 9129 (position in alignment), RU1D and RU1-OR (100\% identity) on one hand, and RU1M, RU1P, RU1W, and US10 (96\% identity) on the other hand, formed two distinct similarity groups (the two groups shared $93 \%$ identity between each other). These patterns of similarity and dissimilarities are presented as a schematic diagram in Figure 3.

\section{DISCUSSION}

Although the $I$ gene is widely used in bean breeding programs $(19,31)$, the exact mechanism conferring resistance to BCMV and of ensuing interactions between the $I$ gene and BCMV or BCMNV is still unknown $(6,7)$. Experiments with isolated protoplasts from isogenic bean lines carrying different numbers of the $I$ alleles demonstrated that BCMV replication in the presence of the $I$ allele is dosage-dependent but even at low temperature $\left(26^{\circ} \mathrm{C}\right)$, BCMV was still able to replicate in the $I$ gene-bearing genotypes, and hence necrosis seemed to occur when the virus was moving from the initially infected cell to a neighboring cell (6). Virusencoded factors and virus genetic determinants involved in interactions between BCMV/BCMNV strains and the $I$ gene in common beans have not been determined yet. There are several factors that have precluded systematic research in this area. So far, there are no full-length infectious clones developed for any of the BCMNV isolates inducing TIN in the presence of the $I$ gene. The two available full-length infectious copies were developed for the BCMV peanut stripe strain (13) and strain RU1 (27), which do not induce TIN $(4,13,22,25,27)$. BCMNV isolates displayed remarkably low biological and molecular diversity belonging to the same pathotype VI, and sharing sequence identity levels above $97 \%$ (21,22), which also did not facilitate studies of BCMNV interactions with the $I$ gene.

RU1 was the only known TSN inducing isolate assigned to the same pathogroup VI with BCMNV isolates $(4,22,25)$. Given the low level of similarity between BCMV and BCMNV sequences (22), this meant that the genetic determinants responsible for the TIN induction and exhibiting pathotype VI in beans are distinct and may reside in different parts of the virus genome. Recently, the RU1 strain was demonstrated to have a substantial biological and molecular diversity, comprising isolates with different recom-

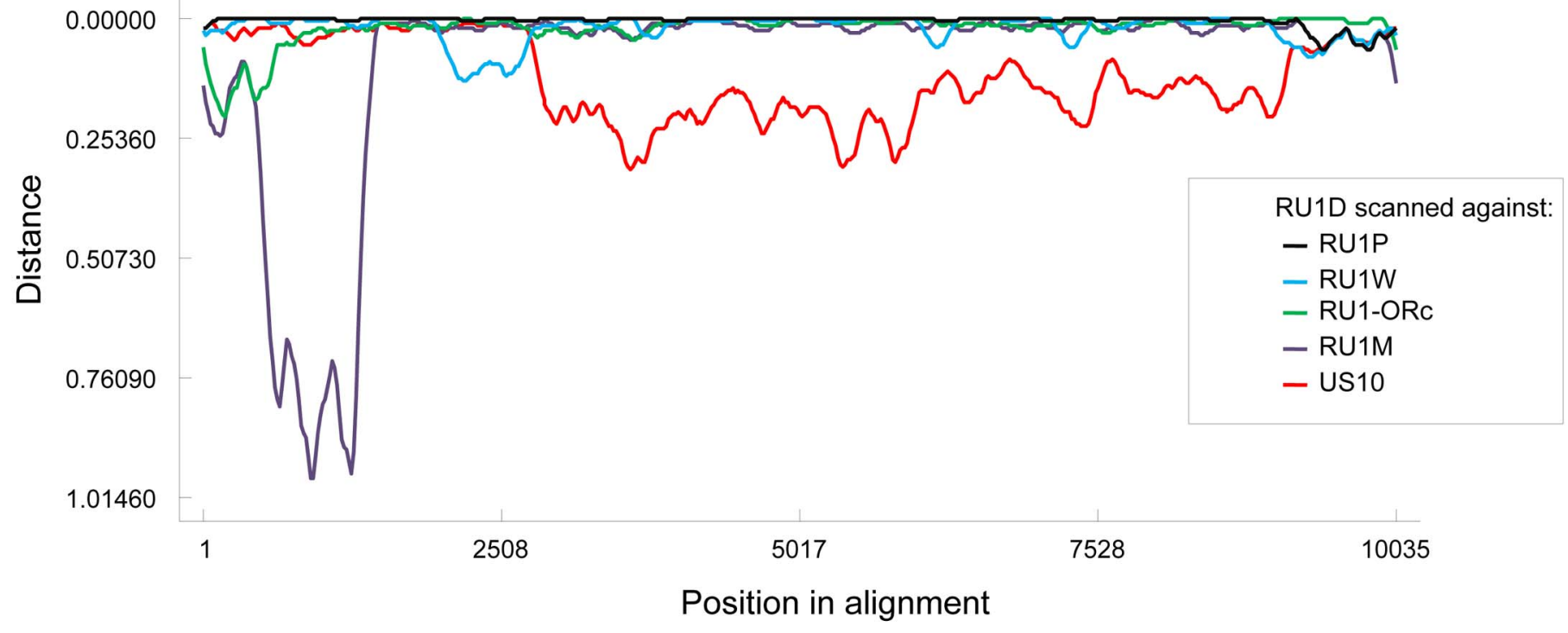

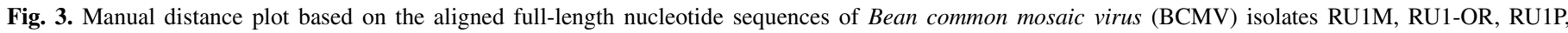

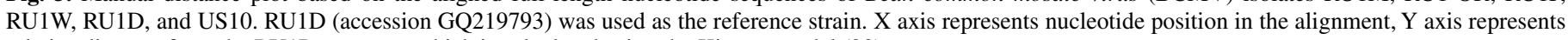
relative distance from the RU1D sequence which is calculated using the Kimura model (20). 
binant structures and exhibiting pathotypes VI and VII (11). Sequence analysis of several whole genomes for BCMV isolates from the RU1 complex suggested that the BCMV RU1 genome region between positions 723 to 1961 could be a putative genetic determinant responsible for pathotype VII, interacting with the $b c-2^{2}$ gene (11). A similar comparative analysis for the BCMNV sequences was not possible because BCMNV genomes sequenced to date exhibited low diversity $(10,21)$.

In this paper, we describe a novel BCMV isolate from the same RU1 complex, RU1M, which was found to have pathotype VII with serotype-B, similar to the control isolate US10 (Tables 1 and 3). But unlike US10 or other RU1-like isolates exhibiting pathotypes VI or VII, RU1M was capable of inducing TIN in an I genebearing cultivar Jubila $(I, b c-1)$. When challenged by RU1M, 'Jubila' plants developed very quick systemic necrosis, or BRS, which caused plant death in only 10 days after inoculation. All four I-bearing cultivars tested, 'Jubila', Amanda, US 1006, and IVT 7233 , harbored the $I$ gene protected by four different recessive genes, and they were expected to exhibit complete resistance to all BCMV isolates. A mild to moderate systemic reaction was expected in cultivar Jubila $(I, b c-1)$ in response to infection with a BCMNV isolate, clearly visible upon infection with isolate TN1 (Fig. 2). However, the response of 'Jubila' plants to the RU1M infection was very different from the expectations either for BCMV or BCMNV infection; in fact, the ensuing BRS was close to a rapid systemic reaction in bean cultivars with a nonprotected $I$ gene following inoculation with BCMNV. Nevertheless, the fact that the $I$ gene was protected in our 'Jubila' plants was confirmed following inoculation with the BCMNV isolate TN1 which produced only mild necrotic reaction in noninoculated leaves very late postinoculation (Fig. 2).

When subjected to the whole genome analysis, RU1M was found very close to the previously sequenced isolate RU1-OR, which also displayed pathotype VII (11). Sequence identity level between RU1M and RU1-OR was found at or above $98 \%$ for the most of the genome with the exception of the $5^{\prime}$-terminal segment spanning the P1 and HC-Pro cistrons (Figs. 3 and 4). The most striking difference between RU1M on one hand, and RU1-OR and all other BCMV genomes on the other hand, was an apparent insert of approximately 770 nucleotides, between nucleotides 513 to 1287 in the P1 encoding region (Figs. 3 and 4). This inserted nucleotide sequence had no close matches to any entry in the GenBank database, although it coded for a potyvirus protein product with $\mathrm{CABMV}$ and BCMNV identified as the closest matches found in GenBank. The identity levels in these cases, below $58 \%$ for CABMV and below $36 \%$ for BCMNV, were too low to suggest a recombination event between BCMV strains; most likely, this insert between positions 513 to 1287 came from an as yet unknown potyvirus. Given the otherwise similar recombinant structure of all RU1-like genomes (Fig. 4), we hypothesize that the presence of this insert in the genome of RU1M may be responsible for the unusual necrotic reaction, BRS, induced by this isolate in bean cultivar Jubila (Fig. 1, Table 1). However, this hypothesis on the location of the genetic determinant responsible for interactions of BCMV with the $I$ gene in common bean still needs to be tested using reverse genetics.

In addition to help in narrowing down the genetic determinant responsible for the interaction between BCMV and the $I$ gene, isolate RU1M might also be helpful in narrowing down other genetic determinants of BCMV, i.e., responsible for interactions between BCMV and $b c-2$ and $b c-2^{2}$ alleles in beans (Fig. 4). Inspection of the RU1M pathogenicity profile and comparison to the genome structures of other RU1-like recombinants (11) suggests that the region coding the N-terminal part of HC-Pro cistron in the BCMV polyprotein, nucleotides 1287 to 1976, may determine pathotype VII isolates, in other words this region may be responsible for interactions with the $b c-2^{2}$ gene (Fig. 4). This 770nucleotide insertion in the RU1M genome thus narrowed down

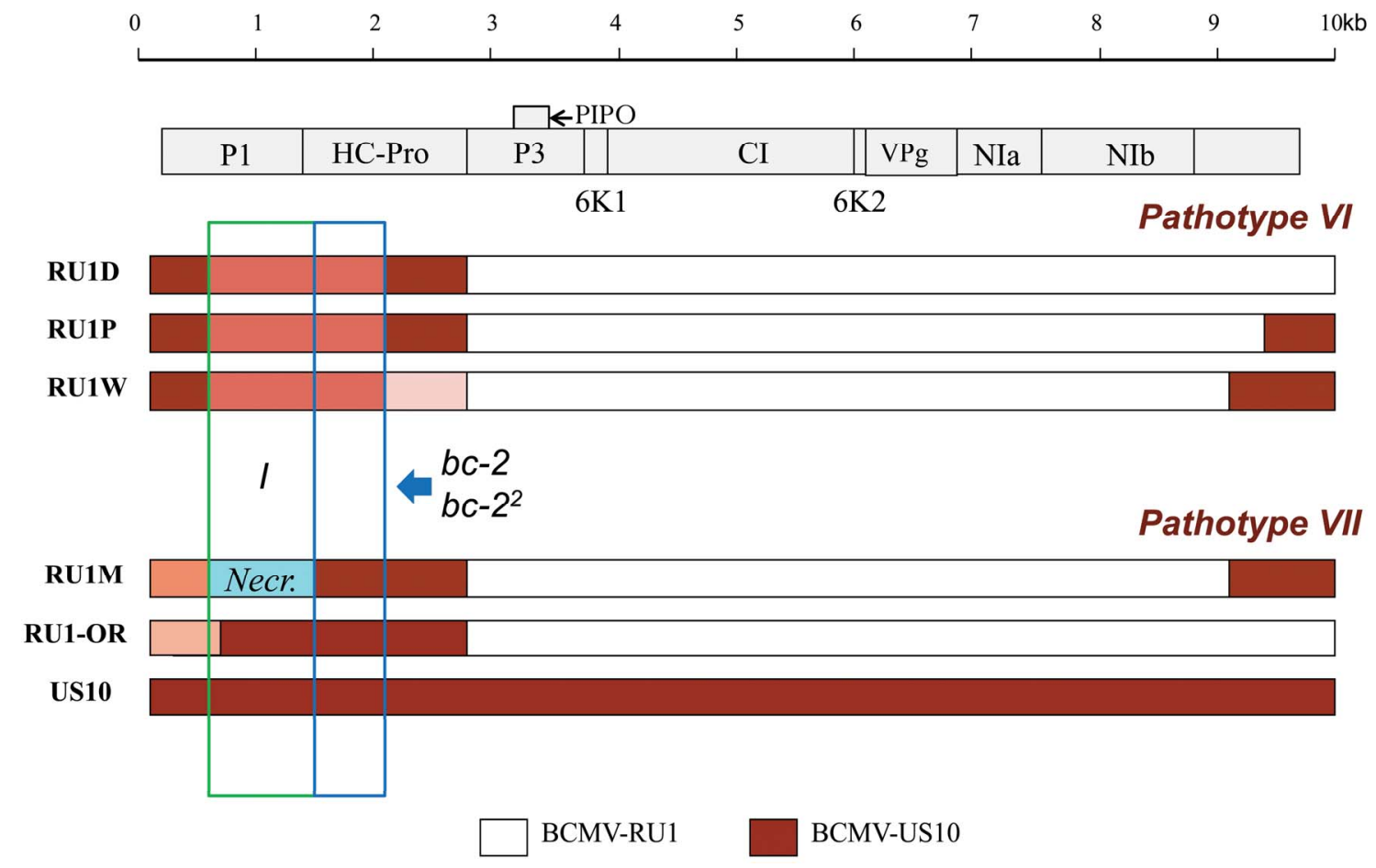

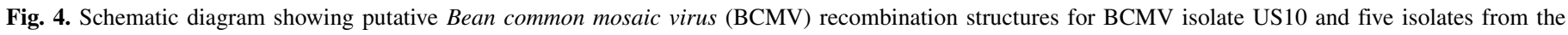

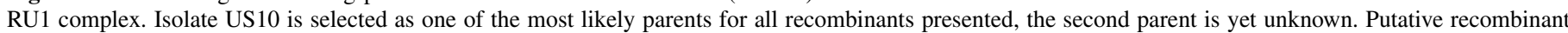

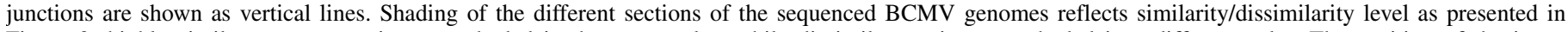

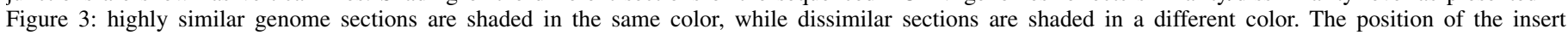

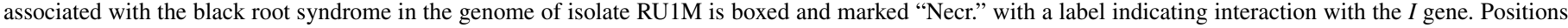

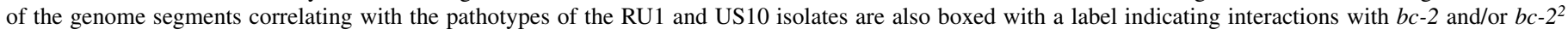
genes. 
considerably the genome region of BCMV hypothesized to be involved in interactions with the $b c-2^{2}$ gene, previously identified between positions 723 and 1976 (11). However, just like in the case of the $I$ gene, all the hypotheses on the locations of genetic determinants responsible for BCMV interactions with recessive $\mathrm{BCMV}$ resistance genes in beans need to be tested using reverse genetic tools.

\section{ACKNOWLEDGMENTS}

We thank P. Berger and P. Shiel for providing reference isolates of BCMV and J. Myers, C. Strausbaugh, and S. Singh for many helpful discussions. This work was funded in part through grants from the Idaho Bean Commission, the Idaho State Department of Agriculture, and by the Idaho Agricultural Experiment Station.

\section{LITERATURE CITED}

1. Adams, M. J., Zerbini, F. M., French, R., Rabenstein, F., Stenger, D. C., and Valkonen, J. P. T. 2011. Family Potyviridae. Pages 1069-1089 in: Virus Taxonomy. Ninth Report of the International Committee on Taxonomy of Viruses. A. King, M. Adams, E. Carstens, and E. Lefkowitz, eds. Elsevier, Oxford, UK.

2. Ali, M. A. 1950. Genetics of resistance to the common bean mosaic virus (bean virus 1) in the bean (Phaseolus vulgaris L.). Phytopathology 40:6979.

3. Altschul, S. F., Madden, T. L., Schaffer, A., Zhang, J., Zhang, Z., Miller, W., and Lipman, D. J. 1997. Gapped BLAST and PSI-BLAST: A new generation of protein database search programs. Nucleic Acids Res. 25:3389-3402.

4. Berger, P. H., Wyatt, S. D., Shiel, P. J., Silbernagel, M. J., Druffel, K., and Mink, M. I. 1997. Phylogenetic analysis of the Potyviridae with emphasis on legume-infecting potyviruses. Arch. Virol. 142:1979-1999.

5. Bos, L. 1971. Bean common mosaic virus. Descriptions of Plant Viruses no. 73. Commonwealth Mycological Institute/Association of Applied Biologists, UK. www.dpvweb.net/dpv/showdpv.php?dpvno=73

6. Cadle-Davidson, M. M., and Jahn, M. 2005. Resistance conferred against Bean common mosaic virus by the incompletely dominant $I$ locus of Phaseolus vulgaris is active at the single cell level. Arch Virol. 150:26012608.

7. Collmer, C. W., Marston, M. F., Taylor, J. C., and Jahn, M. 2000. The $I$ gene of bean: A dosage-dependent allele conferring extreme resistance, hypersensitive resistance, or spreading vascular necrosis in response to the potyvirus Bean common mosaic virus. Mol. Plant-Microbe Interact. 13:1266-1270

8. Drijfhout, E. 1978. Genetic Interaction Between Phaseolus vulgaris and Bean common mosaic virus with Implications for Strain Identification and Breeding for Resistance. Centre for Agricultural Publication and Documents, Wageningen, The Netherlands.

9. Drijfhout, E. 1991. Bean common mosaic. Pages 37-39 in: Compendium of Bean Diseases. American Phytopathological Society, St. Paul, MN.

10. Fang, G. W., Allison, R. F., Zambolim, E. M., Maxwell, D. P., and Gilbertson, R. L. 1995. The complete nucleotide sequence and genome organization of bean common mosaic virus (NL3 strain). Virus Res. 39:13-23.

11. Feng, X., Poplawsky, A. R., Nikolaeva, O. V., Myers, J. R., and Karasev, A. V. 2014. Recombinants of Bean common mosaic virus (BCMV) and genetic determinants of BCMV involved in overcoming resistance in common beans. Phytopathology 104:786-793

12. Fisher, M. L., and Kyle, M. M. 1994. Inheritance of resistance to potyviruses in Phaseolus vulgaris L. III. Cosegregation of phenotypically similar dominant responses to nine potyviruses. Theor. Appl. Genet. 89:818-823.

13. Flasinski, S., Gunasinghe, U. B., Gonzales, R. A., and Cassidy, B. G. 1996. The cDNA sequence and infectious transcripts of peanut stripe virus. Gene 171:299-300.

14. Flores-Estevez, N., Acosta-Gallegos, J. A., and Silva-Rosales, L. 2003. Bean common mosaic virus and Bean common mosaic necrosis virus in Mexico. Plant Dis. 87:21-25.

15. Grogan, R. G., and Walker, J. C. 1948. The relation of common mosaic to black root of bean. J. Agric. Res. (Washington, DC) 77:315-331.

16. Ha, C., Coombs, S., Revill, P. A., Harding, R. M., Vu, M., and Dale, J. L. 2008. Design and application of two novel degenerate primer pairs for the detection and complete genomic characterization of potyviruses. Arch. Virol. 153:25-36.

17. Jenkins, W. A. 1940. A new virus disease of snap beans. J. Agric. Res. (Washington, DC) 60:279-288.

18. Jenkins, W. A. 1941. A histological study of snap bean tissues affected with black root. J. Agric. Res. (Washington, DC) 62:683-690.

19. Kelly, J. D., Afanador, L., and Haley, S. D. 1995. Pyramiding genes for resistance to Bean common mosaic virus. Euphytica 82:207-212.

20. Kimura, M. 1980. A simple method for estimating evolutionary rates of base substitutions through comparative studies of nucleotide sequences. J. Mol. Evol. 16:111-120.

21. Larsen, R. C., Druffel, K. L., and Wyatt, S. D. 2011. The complete nucleotide sequences of bean common mosaic necrosis virus strains NL5, NL-8 and TN-1. Arch. Virol. 156:729-732.

22. Larsen, R. C., Miklas, P. N., Druffel, K. L. and Wyatt, S. D. 2005. NL-3 K strain is a stable and naturally occurring interspecific recombinant derived from Bean common mosaic necrosis virus and Bean common mosaic virus. Phytopathology 95:1037-1042.

23. Martin, D. P., Williamson, C., and Posada, D. 2005. RDP2: Recombination detection and analysis from sequence alignments. Bioinformatics 21:260-262.

24. McKern, N. M., Mink, G. I., Barnett, O. W., Mishra, A., Whittaker, L. A., Silbernagel, M. J., Ward, C. W., and Shukla, D. D. 1992. Isolates of Bean common mosaic virus comprising two distinct potyviruses. Phytopathology 82:923-929.

25. Mink, G. I., and Silbernagel, M. J. 1992. Serological and biological relationships among viruses in the bean common mosaic virus subgroup. Arch. Virol. Suppl. 5:397-406.

26. Morales, F. J., and Bos, L. 1988. Bean common mosaic virus. Descriptions of Plant Viruses No. 337. Commonwealth Mycological Institute/Association of Applied Biologists, UK. http://www.dpvweb.net/ dpv/showdpv.php?dpvno=337

27. Naderpour, M., and Johansen, I. E. 2011. Visualization of resistance responses in Phaseolus vulgaris using reporter tagged clones of Bean common mosaic virus. Virus Res. 159:1-8.

28. Naderpour, M., Lund, O. S., and Johansen, I. E. 2009. Sequence analysis of expressed cDNA of Bean common mosaic virus RU1 isolate. Iran J. Virol. 3:41-43.

29. Pierce, W. H. 1934. Viruses of the bean. Phytopathology 24:87-115

30. Pierce, W. H. 1935. The inheritance of resistance to common bean mosaic in field and garden beans. Phytopathology 25:875-883.

31. Singh, S., and Schwartz, H. F. 2010. Breeding common bean for resistance to diseases: A review. Crop Sci. 50:2199-2223.

32. Strausbaugh, C. A., Miklas, P. N., Singh, S. P., Myers, J. R., and Forster, R. L. 2003. Genetic characterization of differential reactions among host group 3 common bean cultivars to NL-3 K strain of Bean common mosaic necrosis virus. Phytopathology 93:683-690.

33. Vetten, H. J., Lesemann, D. E., and Maiss, E. 1992. Serotype A and B strains of bean common mosaic virus are two distinct potyviruses. Arch. Virol. Suppl. 5:415-431. 